\title{
Prevalence and correlates of chronic obstructive pulmonary disease and chronic respiratory symptoms in rural southwestern Uganda: a cross-sectional, population-based study
}

\author{
Crystal M North ${ }^{1,2,3}$, \\ Bernard Kakuhikire ${ }^{4}$, \\ Dagmar Vořechovská1, \\ Simone Hausammann- \\ Kigozi $^{4}$, Amy Q McDonough ${ }^{1}$, \\ Jordan Downey ${ }^{5}$, David C \\ Christiani ${ }^{1,2,3}$, Alexander C \\ Tsai $^{1,2,4}$, Mark J Siedner ${ }^{1,2,4}$
${ }^{1}$ Massachusetts General Hospital, Boston, Massachusetts, USA
${ }^{2}$ Harvard Medical School, Boston, Massachusetts, USA
${ }^{3}$ Harvard T.H. Chan School of Public Health, Boston, Massachusetts, USA
${ }^{4}$ Mbarara University of Science and
Technology, Mbarara, Uganda
${ }^{5}$ Last Mile Health, Cambridge, Massachusetts, USA

\begin{abstract}
Background The global burden of chronic obstructive pulmonary disease (COPD) disproportionately affects resource-limited settings such as sub-Saharan Africa (SSA), but population-based prevalence estimates in SSA are rare. We aimed to estimate the population prevalence of COPD and chronic respiratory symptoms in rural southwestern Uganda.
\end{abstract}

\begin{abstract}
Methods Adults at least 18 years of age who participated in a population-wide census in rural southwestern Uganda completed respiratory questionnaires and lung function testing with bronchodilator challenge at health screening events in June 2015. We defined COPD as post-bronchodilator forced expiratory volume in one second to forced vital capacity ratio less than the lower limit of normal. We fit multivariable linear and log binomial regression models to estimate correlates of abnormal lung function and respiratory symptoms, respectively. We included inverse probability of sampling weights in models to facilitate population-level estimates.
\end{abstract}

Results Forty-six percent of census participants (843/1814) completed respiratory questionnaires and spirometry, of which 565 (67\%) met acceptability standards. COPD and respiratory symptom population prevalence were 2\% (95\% confidence interval $(\mathrm{CI})=1 \%-3 \%)$ and 30\% (95\% $\mathrm{CI}=25 \%-36 \%$ ), respectively. Respiratory symptoms were more prevalent and lung function was lower among women and ever-smokers $(P<0.05)$. HIV serostatus was associated with neither respiratory symptoms nor lung function.

Conclusions COPD population prevalence was low despite prevalent respiratory symptoms. This work adds to the growing body of literature depicting lower-than-expected COPD prevalence estimates in SSA and raises questions about whether the high respiratory symptom burden in rural southwestern Uganda represents underlying structural lung disease not identified by screening spirometry.

\section{Correspondence to:}

Dr. Crystal M. North, MD MPH

Division of Pulmonary and Critical Care Medicine

Massachusetts General Hospital

55 Fruit Street, BUL-148

Boston, MA, 02118

USA

cnorth@mgh.harvard.edu
Over one billion people worldwide suffer from chronic respiratory diseases. Chronic obstructive pulmonary disease (COPD) is the third leading cause of death and disability globally [1] and has substantial negative impacts on work performance and economic productivity [2]. According to the Global Burden of Disease report, COPD is estimated to be among the top ten causes 
of death in low and middle income countries [1], and modeled estimates based on data through 2010 indicate that over 26 million people are living with COPD in sub-Saharan Africa (SSA) alone [3] - nearly as many as are living with HIV [4]. However, these modeled estimates are based on a limited amount of data from few countries and employ a variety of survey methodologies. Thus, uncertainty remains regarding their accuracy.

Population-based estimates of COPD prevalence in SSA are rare. Cohort studies in SSA have yielded prevalence estimates ranging from $4 \%-25 \%$ depending on the age distribution and prevalence of COPD-associated risk factors in the studied population [3,5], and few studies have used spirometry-based diagnostics or population-based sampling techniques. The only spirometry-based COPD prevalence estimates in Uganda report prevalence estimates ranging from $1.7 \%$ to $16 \%[6,7]$, and there are no prevalence estimates of chronic respiratory symptoms. The prevalence of risk factors for impaired lung function - including air pollution and tobacco exposure, tuberculosis and other lower respiratory tract infections, HIV infection and malnutrition - are different in SSA compared to high income settings, and this differential epidemiology is likely to influence chronic lung disease prevalence [8]. As such, limited data are available to guide regional public health officials in identifying at-risk populations. We conducted spirometry with bronchodilator testing at health screening events in rural southwestern Uganda to estimate the population prevalence of COPD and chronic respiratory symptoms.

\section{METHODS}

This cross-sectional, population-based study was conducted in Nyakabare Parish, a rural community within Mbarara district, southwestern Uganda. Most residents of Mbarara district practice subsistence farming [9] and live in rural settings where both food and water insecurity are common [10,11].

Most eligible adults in Nyakabare Parish (98\%, 1814/1851) were enumerated in a population census conducted from 2014 to 2015. The census sought to enroll all adults aged 18 years and older (and emancipated minors aged 16 to 18 years) who reported having stable, primary residence in Nyakabare Parish. There were no other inclusion or exclusion criteria. Adults at least 18 years of age who participated in the population census were invited to attend one of five health screenings in June 2015 (Figure S1 in Online Supplementary Document), and those who attended were eligible for study participation. The health screenings were advertised through community meetings, printed advertisements, and radio and church announcements. Free transportation was arranged for community members with poor health or limited mobility.

Trained study staff collected demographic and health information with structured questionnaires (Figure S2 in Online Supplementary Document). Study staff included research assistants who administered study questionnaires, phlebotomists who collected blood samples, and medical professionals and students who conducted the medical screenings. Smoking history was collected with a modified WHO STEPS questionnaire [12]. Participants were identified as having a chronic cough and/or chronic dyspnea if they responded "yes" to the following questions: 1) "Do you have a cough on most days?" and/or 2) "Do you have difficulty in breathing on most days?" Participants who reported a cough were asked about sputum production. Body mass index was calculated by dividing weight (in kilograms) by height squared (in centimeters). Confidential HIV testing was offered in accordance with national guidelines [13].

Trained volunteers measured forced expiratory volume in one second $\left(\mathrm{FEV}_{1}\right)$ and forced vital capacity (FVC) with EasyOne ${ }^{\circledR}$ Plus handheld spirometers (nDD Medical Technologies, Andover, USA) in accordance with American Thoracic Society (ATS) standards [14]. Spirometers were factory-calibrated prior to use, and multi-flow calibration was confirmed using a 3-L syringe after the final day of study procedures. All subjects had refrained from smoking for at least one hour prior to testing. Four puffs of albuterol (Ventolin, GlaxoSmithKline, Philadelphia, PA, USA) were administered to participants with $\mathrm{FEV}_{1}$ :FVC $<0.7$ and spirometry was repeated after 10 minutes.

An external spirometry review committee (Health Research Associates, Concord, USA) reviewed all tests for ATS acceptability and repeatability. Results were interpreted using National Health and Nutrition Examination Survey III (NHANES III) prediction equations with African American correction factors [15] and standard interpretation criteria [16]. NHANES III prediction equations were chosen based on similarities with east African prediction equations [17]. Tests were considered reproducible if the FEV ${ }_{1}$ and FVC from the two best trials were within $200 \mathrm{~mL}$ (mL) of one another. Tests with only two trials were included if they met repeatability criteria. COPD was defined as a post-bronchodilator $\mathrm{FEV}_{1}$ : $\mathrm{FVC}$ less than the fifth percentile of the predicted values (lower limit normal; LLN), which were defined using NHANES III prediction equations. 
All study procedures were conducted in accordance with the guidelines of the Declaration of Helsinki and were approved by the Mbarara University of Science and Technology and Partners Healthcare human studies ethics committees, the Uganda National Council for Science and Technology, and the Research Secretariat in the Office of the President (Uganda). All study participants provided written informed consent.

\section{STATISTICAL ANALYSIS}

To evaluate for selection bias, cohort demographics were compared between 1) health screenings attendees and non-attendees, 2) attendees who completed and declined spirometry, and 3) attendees with ATS acceptable and unacceptable spirometry.

Inverse probability of treatment weights (IPTW) were used to estimate population prevalence, whereby we first estimated the propensity to participate in the health fair using a logistic regression model consisting of 15 variables collected during the census that were expected to correlate with health fair attendance: age, sex, education level, marital status, village of residence, household asset wealth, distance from the health fair, difference between household altitude and health fair altitude, self-reported overall health, self-reported HIV status, heavy alcohol use, social network size, index of social participation, water insecurity and food insecurity. We defined household asset wealth using the method developed by Filmer and Pritchett [18], social network size as the total number of unique social network ties elicited in response to a series of culturally-adapted social network name generator questions (which can be informally understood as a participant's total number of "friends") [19], social participation as the number of different community groups in which the participant reported significant participation in the previous two months [20], and water and/or food insecurity as having limited or uncertain availability of safe water and/or nutritious food or lacking the ability to acquire safe water and/or nutritious food in socially acceptable ways [10,21]. We using this model to calculate stabilized IPTWs using methods developed by Hernan et al [22].

Nyakabare Parish-representative estimates of COPD and respiratory symptom prevalence were generated by incorporating IPTWs using the svy command in Stata (StataCorp LLC, College Station, TX, USA), and sensitivity to extreme IPTW weights was assessed by excluding those with weights at the 99th/1st, 95th/5th and 90th/10th percentiles. Our primary outcome of interest was lung function, as measured by $\mathrm{FEV}_{1}$ and $\mathrm{FEV}_{1}$ : FVC. Our secondary outcome of interest was chronic respiratory symptoms, defined as either chronic cough or chronic dyspnea. Explanatory covariates of interest were chosen based on the scientific plausibility of their association with either lung function or respiratory symptoms and included age, sex, smoking history, education level, household asset index (as a measure of socioeconomic status [18]), body mass index and HIV serostatus. The joint statistical significance of regression coefficients on categorical variables (eg, household asset index quintiles) was evaluated using a Wald-type F-test.

Multivariable log binomial regression models were fit to estimate associations between chronic respiratory symptoms and covariates of interest, and multivariable linear regression models were fit to estimate associations between lung function and covariates of interest. Participants with missing data for any model covariates were excluded from analyses. Sensitivity analyses were conducted in which the study population was restricted to a) participants at least 40 years of age, and b) those for whom the

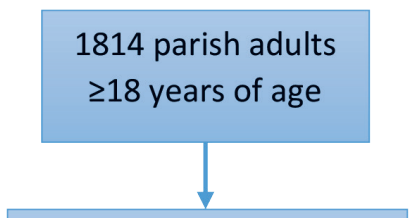

$856(47 \%)$ attended health screening events

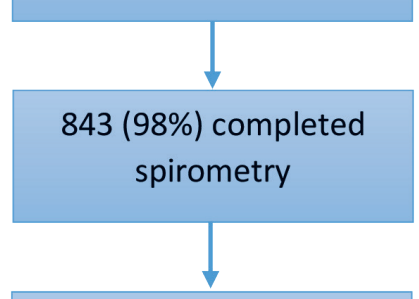

In 565 (67\%) spirometry met ATS criteria two best spirometry trials were within $150 \mathrm{~mL}$ of one another. Data were analyzed using Stata 13 (StataCorp LLC, College Station, TX, USA).

\section{RESULTS}

Out of 1814 enumerated Nyakabare Parish residents, 47\% (n=856) attended the health screenings, most of whom $(98 \%, 843 / 856)$ completed medical questionnaires and spirometry (Figure 1). Most spirometry $(67 \%, \mathrm{n}=565)$ met interpretation criteria. Compared with those who did not attend the health fairs, participants who attended were

Figure 1. Flow diagram of participant selection. Flow diagram describing the number of eligible participants in the target region, how many eligible participants sought screening at the health fair, and how many of those who sought screening completed respiratory questionnaires and American Thoracic Society (ATS)acceptable pulmonary function testing. Those who completed respiratory questionnaires and ATS-acceptable pulmonary function testing were used to calculate respiratory symptom burden and COPD prevalence estimates, respectively. 
older, more commonly women, less educated, and reported lower subjective health $(P<0.001$ for all comparisons, Supplementary Table S1 in the Online Supplementary Document). There were no statistically nor substantively significant differences between those who completed spirometry as compared to those who declined spirometry, or between those whose spirometry met ATS standards as compared to those whose spirometry was unacceptable (Tables S2 and S3 in Online Supplementary Document).

Using IPTWs to model population-level data, the population was half women (52\%), with a mean age of $39 \pm 17$ years, most of whom (75\%) had never smoked (Table 1). Over half (59\%) had completed at most a primary school education, 62\% were subsistence farmers, HIV prevalence was $5 \%$, and few had been diagnosed with COPD (1\%) or asthma (1\%). These estimates are similar to general Ugandan population demographics $[9,23]$. Chronic respiratory symptoms were reported by $30 \%$ of the population, which was unchanged when excluding participants with bronchodilator-associated reversibility on spirometry (Table 2). Among those who reported a cough, most (70\%) reported regular sputum production.

Mean percent predicted lung function was normal. Population prevalence of COPD was 2\%, which was unchanged when defining COPD as $\mathrm{FEV}_{1}: \mathrm{FVC}<0.7$ or restricting acceptable spirometry to that in which the best trials were within $150 \mathrm{~mL}$ of one another (Table 2). Prevalence increased minimally to $3 \%$ when limiting the cohort to participants at least 40 years old, and estimates were similar when utilizing trimmed weights. COPD prevalence was higher among older individuals $(P=0.005)$ and ever-smokers $(P=0.002)$ (Table S4 in Online Supplementary Document).

In multivariable log binomial regression models adjusted for potential confounders, the prevalence of chronic respiratory symptoms was $71 \%$ higher among women $(P=0.006)$ and $50 \%$ higher among current or former smokers $(P=0.04)$ (Table S5 in the Online Supplementary Document). In multivariable linear regression models adjusted for potential confounders, $\mathrm{FEV}_{1}$ and $\mathrm{FEV}_{1}: \mathrm{FVC}$ were lower among women and ever-smokers (Table 3). Conversely, FEV 1 was higher among older individuals. Effect estimates were similar in sensitivity analyses (Tables S6-S10 in Online Supplementary Document).

Table 1. Cohort characteristics of participants who completed ATS-acceptable spirometry and population characteristics

\begin{tabular}{|c|c|c|}
\hline Characteristic & UnWEIGHTED STUdY SAMPIE ( $N=565)^{*}$ & Population weighted estimates \\
\hline Age, years (mean, standard deviation) & $43 \pm 17$ & $39 \pm 17$ \\
\hline Women & $62 \%(n=348)$ & $52 \%$ \\
\hline \multicolumn{3}{|l|}{ Smoking history: } \\
\hline Never smoker & $71 \%(n=398)$ & $75 \%$ \\
\hline Former smoker & $19 \%(n=107)$ & $15 \%$ \\
\hline Current smoker & $10 \%(\mathrm{n}=57)$ & $10 \%$ \\
\hline Years smoked $\dagger$ & $20( \pm 17)$ & $20( \pm 16)$ \\
\hline Farmer & $71 \%(n=399)$ & $62 \%$ \\
\hline \multicolumn{3}{|l|}{ Body mass index $\left(\mathrm{kg} / \mathrm{m}^{3}\right)$ : } \\
\hline Underweight $(<18.5)$ & $5 \%(n=26)$ & $4 \%$ \\
\hline Normal (18.5-25) & $54 \%(n=305)$ & $61 \%$ \\
\hline Overweight (25.1-30) & $26 \%(n=147)$ & $22 \%$ \\
\hline Obese $(\geq 30)$ & $15 \%(\mathrm{n}=87)$ & $12 \%$ \\
\hline \multicolumn{3}{|l|}{ Education: } \\
\hline None & $17 \%(\mathrm{n}=95)$ & $13 \%$ \\
\hline Some primary school & $32 \%(n=182)$ & $24 \%$ \\
\hline Completed primary school & $25 \%(n=142)$ & $22 \%$ \\
\hline At least some secondary school & $26 \%(n=146)$ & $40 \%$ \\
\hline \multicolumn{3}{|l|}{ Medical comorbidities: $\ddagger$} \\
\hline COPD & $1 \%(n=4)$ & $1 \%$ \\
\hline Asthma & $2 \%(\mathrm{n}=9)$ & $1 \%$ \\
\hline HIV & $5 \%(\mathrm{n}=25)$ & $5 \%$ \\
\hline
\end{tabular}

ATS - American Thoracic Society, COPD - chronic obstructive pulmonary disease, HIV - human immunodeficiency virus *Missing data were present for the following covariates - Smoking history: 1\% ( $\mathrm{n}=3)$; Farmer: 6\% ( $\mathrm{n}=33)$; HIV: 12\% ( $\mathrm{n}=65)$; COPD: $2 \%(n=12)$; Asthma: $1 \%(n=5)$.

$\dagger$ Current or former smokers only.

¥COPD and Asthma were self-reported. HIV serostatus was confirmed with antibody testing. 
Table 2. Mean lung function (\% predicted), COPD prevalence and cough/dyspnea prevalence, under progressive truncation of overall weights*

\begin{tabular}{|c|c|c|c|c|c|}
\hline \multirow[t]{2}{*}{ Outcome } & \multirow[t]{2}{*}{$\begin{array}{l}\text { TOTAL POPULATION } \\
\quad(\mathrm{N}=565)\end{array}$} & \multirow[t]{2}{*}{$\begin{array}{l}\text { WEIGHTED POPULATION ESTIMATE } \\
\text { WITHOUT TRIMMING ( } 95 \% \text { CI) }\end{array}$} & \multicolumn{3}{|c|}{ Trimmed ${ }^{\dagger}$ welGHt POPULATION ESTIMATES (95\% CI) } \\
\hline & & & $99^{\text {th }}, 1^{\text {st }}$ percentile & $95^{\text {th }}, 5^{\text {th }}$ percentile & $90^{\text {th }}, 10^{\text {th }}$ percentile \\
\hline $\mathrm{FEV}_{1}(\%$ predicted $)$ & $99.1(19.4)$ & $100.2(98.1,102.3)$ & $99.6(97.9,101.3)$ & $99.3(97.7,100.9)$ & $99.2(97.6,100.7)$ \\
\hline FVC (\% predicted) & $100.9(17.9)$ & $101.7(100.0,103.5)$ & $101.2(99.7,102.8)$ & $101.0(99.5,102.4)$ & $100.9(99.4,102.3)$ \\
\hline $\mathrm{FEV}_{1}:$ FVC (\% predicted) & $97.9(7.3)$ & $98.7(97.6,99.7)$ & $98.5(97.7,99.2)$ & $98.4(97.6,99.0)$ & $98.2(97.6,98.9)$ \\
\hline COPD prevalence & 2.3 & $1.6(0.9,2.9)$ & $1.7(1.0,3.1)$ & $1.9(1.0,3.3)$ & $2.0(1.1,3.5)$ \\
\hline -Age $\geq 40 \ddagger$ & 3.3 & $2.9(1.4,5.7)$ & $2.9(1.4,5.7)$ & $3.0(1.5,5.9)$ & $3.1(1.5,6.1)$ \\
\hline -Best values $\leq 150 \mathrm{~mL} \&$ & 2.5 & $2.0(0.9,4.3)$ & $2.2(1.0,4.6)$ & $2.3(1.1,4.8)$ & $2.3(1.2,4.4)$ \\
\hline Cough/dyspnea prevalence & 35.0 & $30.3(25.1,36.0)$ & $32.2(27.6,37.1)$ & $33.1(28.8,37.7)$ & $33.4(29.3,37.8)$ \\
\hline -Excluding BD reversibility & 35.0 & $30.1(24.9,35.9)$ & $32.0(27.4,37.0)$ & $32.9(28.6,37.5)$ & $33.2(29.2,37.6)$ \\
\hline
\end{tabular}

CI - confidence interval, FEV 1 - Forced expiratory volume in one second, FVC - Forced vital capacity, \% - predicted: percent predicted using National Health and Nutrition Examination Survey III prediction equations, COPD - chronic obstructive pulmonary disease, BD - bronchodilator

* Mean (standard deviation) or weighted population mean (95\% CI) unless otherwise noted.

$\uparrow$ Trimmed weights replace values above and below the respective percentiles (eg, $99^{\text {th }} / 1^{\text {st }}$ percentile) with the values at that percentile to ensure estimates are not excessively sensitive to extreme values

$\neq \mathrm{n}=274$.

$\S \mathrm{n}=397$.

Table 3. Population-weighted unadjusted and adjusted correlates of lung function*

\begin{tabular}{|c|c|c|c|c|c|c|c|c|}
\hline \multirow{3}{*}{ Characteristic } & \multicolumn{4}{|c|}{ FEV ( $\%$ PREDICTED) } & \multicolumn{4}{|c|}{ FEV $V_{1}$ FVV (\% PREDICTED) } \\
\hline & \multicolumn{2}{|c|}{ Unadjusted } & \multicolumn{2}{|c|}{ Adjusted } & \multicolumn{2}{|c|}{ Unadjusted } & \multicolumn{2}{|c|}{ Adjusted } \\
\hline & $\% \Delta$ & $95 \%$ CI & $\% \Delta$ & $95 \%$ CI & $\% \Delta$ & $95 \%$ CI & $\% \Delta$ & $95 \%$ CI \\
\hline Age, per year & 0.08 & $-0.01,0.17$ & 0.15 & $0.03,0.26$ & 0.01 & $-0.02,0.05$ & 0.04 & $-0.01,0.08$ \\
\hline Female sex & -5.15 & $-8.04,-2.26$ & -6.02 & $-9.31,-2.73$ & -4.36 & $-5.51,-3.20$ & -4.36 & $-5.66,-3.06$ \\
\hline Smoking & -0.18 & $-3.55,3.18$ & -5.91 & $-10.41,-1.42$ & -0.39 & $-1.79,1.01$ & -2.31 & $-4.09,-0.54$ \\
\hline Cough or dyspnea & -4.97 & $-8.15,-1.79$ & -2.53 & $-5.98,0.92$ & -1.73 & $-3.06,-0.41$ & -0.63 & $-1.99,0.73$ \\
\hline \multicolumn{9}{|c|}{ Asset ownership index: } \\
\hline -Poorest & -2.95 & $-7.51,1.60$ & -0.58 & $-5.52,4.35$ & -1.87 & $-3.75,0.01$ & -1.66 & $-3.62,0.29$ \\
\hline -Poorer & 0.82 & $-3.90,5.53$ & 1.50 & $-3.59,6.60$ & -0.32 & $-2.26,1.63$ & -0.42 & $-2.43,1.59$ \\
\hline -Middle & 4.10 & $-0.12,8.30$ & 4.62 & $0.14,9.10$ & 1.45 & $-0.29,3.18$ & 0.29 & $-1.49,2.06$ \\
\hline -Richer & 1.03 & $-3.53,5.58$ & 0.87 & $-4.02,5.76$ & 1.65 & $-0.23,3.53$ & 0.13 & $-1.80,2.06$ \\
\hline HIV & -5.18 & $-12.09,1.73$ & -5.71 & $-12.76,1.33$ & -1.32 & $-4.14,1.49$ & -1.07 & $-3.85,1.72$ \\
\hline
\end{tabular}

$\mathrm{FEV}_{1}$ - Forced expiratory volume in one second, FVC - Forced vital capacity, \% predicted - percent predicted using National Health and Nutrition Examination Survey III prediction equations, $\% \Delta$ - percent change, CI - confidence interval, HIV - human immunodeficiency virus

* Missing data were present for the following model covariates: smoking history: $1 \%(n=3)$; cough or dyspnea: $1 \%(n=7)$; asset ownership index: 1\% ( $n=5)$; HIV: 12\% $(n=65)$. Reference categories for comparisons: Smoking - lifelong non-smoker; Asset ownership index - Richest quintile

\section{DISCUSSION}

In rural southwestern Uganda, we estimated a lower than expected population prevalence of COPD despite a high respiratory symptom burden. Our results add to a growing body of literature investigating the burden of COPD-related morbidity and mortality across SSA that may challenge widely held assumptions that COPD is among the top chronic health conditions in the region.

This study adds to a handful of population-based studies in SSA demonstrating a low prevalence of COPD (Table 4) [7,25-28]. Our COPD prevalence estimates are similar to those described by Siddharthan and Grigsby et al., who found that COPD population prevalence in Uganda ranged from 1.7\% to $7.4 \%$ among urban and rural Ugandan cohorts, respectively, despite nearly ubiquitous biomass exposure [7]. There are several potential explanations for the lower-than-expected COPD prevalence in our cohorts. First, biomass smoke exposure is predicted to be the leading cause of COPD in SSA [38], yet a recent multi-site study of 18554 adults across 25 different sites found no relationship between biomass exposure and COPD [39]. Biomass smoke-associated COPD is characterized by more small airways disease, less emphysema and a slower FEV 1 decline over time as compared to cigarette smoke-associated COPD [40,41]. Thus, studies utilizing imaging to evaluate structural lung abnormalities may be necessary to better understand the true burden of biomass-associated lung disease. 
Table 4. COPD prevalence estimates in sub-Saharan Africa

\begin{tabular}{|c|c|c|c|c|c|c|}
\hline FIRST AUTHOR & Publication year & Counitiy & Setring & SAMPLE SIZE & Mean age (years) & COPD PREVALENCE \\
\hline Siddharthan, Grigsby [7] & 2018 & Uganda & Urban & 596 & 44.2 & $1.7 \%$ \\
\hline Siddharthan, Grigsby [7] & 2018 & Uganda & Rural & 721 & 49.1 & $7.4 \%$ \\
\hline Magitta [24] & 2018 & Tanzania & Rural & 496 & 51.8 & $11.1 \%$ \\
\hline Pefura-Yone [25] & 2016 & Cameroon & Urban & 1,287 & 34.4 & $2.4 \%$ \\
\hline Meghji [26] & 2016 & Malawi & Urban & 748 & 41.9 & $4.2 \%$ \\
\hline Obaseki [27] & 2016 & Nigeria & Urban & 875 & Not provided & $7.7 \%$ \\
\hline van Gemert [6] & 2015 & Uganda & Rural & 588 & 45 & $16.2 \%$ \\
\hline Musafiri [28] & 2011 & Rwanda & Urban/Rural & 1,824 & 38.3 & $4.5 \%$ \\
\hline Fullerton [29] & 2011 & Malawi & Urban/Rural & 332 & 46 & $13.6 \%$ \\
\hline Khelafi [30] & 2011 & Algeria & Urban/Rural & 1800 & 47.5 & $4.9 \%$ \\
\hline Martins [31] & 2009 & Cape Verde & Urban/Rural & 274 & 41.7 & $8.4 \%$ \\
\hline Girdler-Brown [32] & 2008 & South Africa & Prior gold miners & 624 & 49.4 & $13.4 \%$ \\
\hline Buist [33] & 2007 & South Africa & Urban & 847 & 53.6 & $23.8 \%$ \\
\hline Gathuru [34] & 2002 & Nigeria & Urban & 270 & 47.6 & $9.3 \%$ \\
\hline Oleru, Onyekwere [35] & 1992 & Nigeria & Urban shoe factory & 134 & 33.1 & $6.8 \%$ \\
\hline Myers, Cornell [36] & 1989 & South Africa & Urban brick workers & 268 & 29.6 & $4.1 \%$ \\
\hline Wicht [37] & 1977 & South Africa & Urban & 509 & $(20-79)$ & $9.3 \%$ \\
\hline
\end{tabular}

COPD - Chronic obstructive pulmonary disease

Several additional explanations may also contribute to the lower-than-expected COPD population prevalence. Lower $\mathrm{FEV}_{1}$ is associated with increased all-cause and respiratory mortality [42], so survivorship bias may have caused us to underestimate the prevalence of COPD in the general population. Consistent with this theory, we found that older age was paradoxically associated with better lung function. Indeed, while still lower than expected, the unadjusted COPD prevalence was highest within the oldest quartile of our study participants. Additionally, smoking is less common in SSA compared to high-income countries, and for those who do smoke, the overall tobacco exposure is much lower [43]. Thus, tobacco exposure in this and other SSA cohorts may not be high enough to cause the burden of COPD seen in populations with higher tobacco exposure.

Importantly, several studies in SSA have measured higher COPD prevalence compared to our results. Investigators in the Masindi district of western Uganda diagnosed COPD in 16\% of 588 adults [6]. Our cohorts are quite similar in terms of age, sex, educational attainment, occupation, and HIV prevalence. Though we did not collect biomass exposure data in this cohort, other work in the Mbarara District of southwestern Uganda confirms ubiquitous biomass exposure $[44,45]$ similar to that reported in the Masindi cohort. The differences in our COPD prevalence estimates may be related to variations in tobacco exposure, urban vs rural environment, and tribal ancestry. The Masindi District is one of the main tobacco growing regions in Uganda [46], and more of the Masindi cohort participants are current or former smokers as compared to our cohort (36\% vs 29\%) [47]. Additionally, 17\% of the Masindi cohort lives in urban regions, where lung disease risks such as air pollution are more prevalent, while our cohort resides entirely in a rural setting. Lastly, tribal ancestry differs between western and southwestern Uganda. The major tribes of the Masindi district in western Uganda are the Banyoro and Lugbara, while southwestern Uganda is populated mainly by people of Banyankole descent [48], and differences in ethnicity are associated with variations in lung function [49].

The highest COPD population prevalence estimate in SSA was measured in urban South Africa, where $24 \%$ of cohort participants were diagnosed with COPD [33]. While tobacco exposure was also higher in the South African cohort, tuberculosis incidence in South Africa is among the highest in the world, and post-tuberculosis obstructive lung disease is emerging as a commonly-described post-infectious complication [50]. Our COPD population prevalence estimates are also lower than the prevalence estimates from two recent meta-analyses of spirometry-based studies in SSA. Based on data from seven African studies from 1999 to 2010, Adeloye and colleagues estimate that 10.6-13.4\% of the aggregate study population has COPD [3,51]. Heterogeneity in study methods and cohort characteristics among the analyzed studies, including several that estimate cohort prevalence rather than population prevalence, may explain the differences compared to our prevalence estimates. 
We found that lung function was lower among women and ever-smokers, consistent with published literature $[52,53]$. At similar levels of tobacco exposure, female smokers have higher COPD risk and more accelerated lung function decline compared to male smokers, [53] which may be related to sex-based risk differences [54]. In Uganda and elsewhere in SSA, women are also disproportionately exposed to biomass smoke due to sex-based meal preparation roles [55]. As noted above, associations between biomass smoke exposure and impaired lung function have been found by some [7] but not all [39] investigators, and thus require further study in the context of our findings. We found no associations between HIV serostatus and lung function, consistent with some [26] but not all [56] studies in SSA. Chronic HIV infection increases risk for COPD due to virus-associated chronic inflammation and immune activation [57], which takes many years to develop. The HIV-infected individuals in our cohort were at varying stages of disease, which may explain the lack of association.

\section{Respiratory symptom prevalence}

Ours is the first study to estimate the population burden of chronic respiratory symptoms in rural Uganda. In contrast to COPD prevalence, we found an unexpectedly high prevalence of chronic respiratory symptoms in this cohort. There are several hypotheses that may explain the discrepancies in these prevalence estimates. First, respiratory symptoms are often caused by extra-pulmonary disease. For example, the differential diagnosis of chronic cough includes post-nasal drip and gastroesophageal reflux, and allergic upper airway irritation can cause cough and sputum production [58]. Cardiac dysfunction can also cause cough and dyspnea $[59,60]$. Though cardiac arrhythmias were uncommon in this cohort [61], we did not evaluate cardiac function per se. Second, respiratory symptoms may be due to non-obstructive lung disease. For instance, though we did not estimate the prevalence of restrictive lung disease in this cohort, investigators in Malawi found that 38.6\% of 749 urban adults had restrictive physiology while only $3.6 \%$ had moderate to severe airways obstruction [26]. Spirometry more readily identifies airways abnormalities compared with lung parenchymal abnormalities. Pulmonary tuberculosis and other lower respiratory tract infections are prevalent in sub-Saharan Africa [62,63] and can cause subsequent interstitial lung abnormalities $[64,65]$. Air pollution exposure has also been associated with interstitial lung abnormalities in adults and children [66,67]. It is possible that the participants in our cohort with respiratory symptoms and normal spirometry may have undiagnosed interstitial lung disease that would be more accurately identified with chest computed tomography. To investigate these hypotheses, we are now planning to collect high-resolution chest computed tomography imaging in a subset of study participants to further characterize the burden of chronic respiratory disease in this cohort.

The prevalence of chronic cough in the study population was over 10 times higher than estimates from a meta-analysis of African studies [68]. Although a handful of prior studies have reported similar respiratory symptom prevalence estimates in Uganda, Nigeria, South Africa and Malawi [69-72], prevalence estimates in similarly rural locations are often much lower. For example, participants in a longitudinal cohort of HIV-infected adults on antiretroviral therapy in rural Uganda reported chronic cough at $10 \%$ of study visits [45]. Similarly, the prevalence of cough was $7.5 \%$ among a community-based cohort of Malawian adults [26], 1.2\% among rural Gambian adults [73], and 5\% among a cohort of Rwandan adults [28]; although the definitions of cough varied among these studies.

The high respiratory symptom prevalence in our rural cohort may be related to air pollution sources such as biomass fuels. Consistent with published literature, respiratory symptom prevalence was significantly higher among women, who may experience higher exposure to inhaled irritants from biomass-related household air pollution [55] or have a more sensitive cough reflex when compared to men [74]. As previously described, women may also be more susceptible to the respiratory effects of inhalation-based exposures $[53,54]$. Compared to SSA cohorts reporting lower respiratory symptom prevalence, home biomass exposure in our cohort was ubiquitous.

The main strength of this analysis is the use of a large, population-based cohort with complete demographic data on those who did not complete study procedures, which allowed us to calculate population disease prevalence estimates. This study also has several limitations. First, only half of the study cohort attended the health screenings, which may have introduced selection bias if those with previously diagnosed COPD and/or those in poor health were less likely to attend. However, spirometry availability in the region is minimal and travel was facilitated for those in poor health, which limits the influence of potential selection bias on our prevalence estimates. Second, those who completed health screenings were older and more likely to feel unhealthy, which may have caused us to overestimate COPD prevalence. However, the measured COPD prevalence was lower than expected, so any potential upward bias that 
may have resulted would only further accentuate our conclusion that COPD is uncommon. The IPTW estimates also leveraged data from the entire cohort to produce population-representative estimates based on data obtained from those who did not attend the health screenings, although population-weighted prevalence estimates may not fully represent the true population prevalence if prevalence varies by some unmeasured confounder. Third, about one third of spirometry results did not meet interpretation criteria, but there were no statistically significant differences between participants with and without acceptable spirometry, so this is unlikely to have systematically biased our results. Additionally, bronchodilator was only administered to those with FEV1/FVC $<0.7$ rather than those with FEV1/FVC $<$ LLN due to automated spirometer algorithms, which may have caused us to underestimate COPD prevalence in this younger cohort. However, COPD prevalence estimates were similar when restricting the cohort to those over 40 years old. Also, our study participants were drawn from one region in rural southwestern Uganda, and COPD prevalence may vary by region due to differences in risk factors or health-related behaviors. While our estimates vary from those described in rural western Uganda, they are similar to those described in rural central Uganda, which further emphasizes the importance of measuring disease prevalence in various locations. Lastly, no data were collected on biomass fuel exposure, but biomass use in this region is ubiquitous[45] and thus unlikely to have biased our results.

\section{CONCLUSIONS}

In conclusion, COPD prevalence among adults attending health screenings in rural southwestern Uganda is low despite prevalent respiratory symptoms. If the results of our work are corroborated, further work is needed to evaluate whether the underlying etiology of the high respiratory symptom burden in rural southwestern Uganda represents underlying structural lung disease not identified by screening spirometry.

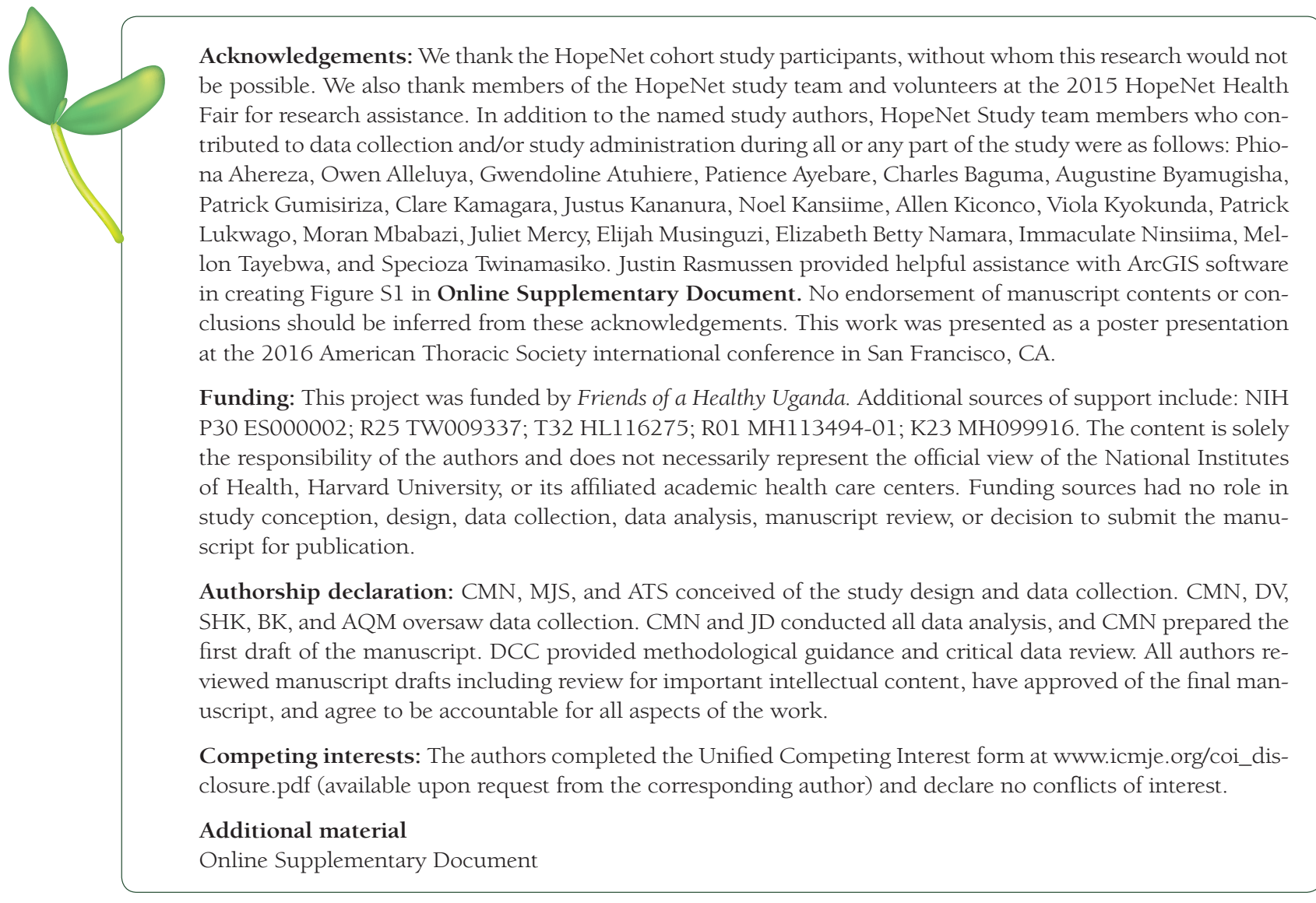


1 GBD 2015 Mortality and Causes of Death Collaborators. Global, regional, and national life expectancy, all-cause mortality, and cause-specific mortality for 249 causes of death, 1980-2015: a systematic analysis for the Global Burden of Disease Study 2015. Lancet. 2016;388:1459-544. Medline:27733281 doi:10.1016/S0140-6736(16)31012-1

2 Chaker L, Falla A, van der Lee SJ, Muka T, Imo D, Jaspers L, et al. The global impact of non-communicable diseases on macro-economic productivity: a systematic review. Eur J Epidemiol. 2015;30:357-95. Medline:25837965 doi:10.1007/ s10654-015-0026-5

3 Adeloye D, Basquill C, Papana A, Chan KY, Rudan I, Campbell H. An estimate of the prevalence of COPD in Africa: a systematic analysis. COPD. 2015;12:71-81. Medline:24946179 doi:10.3109/15412555.2014.908834

4 Evans GW, Kantrowitz E. Socioeconomic status and health: the potential role of environmental risk exposure. Annu Rev Public Health. 2002;23:303-31. Medline:11910065 doi:10.1146/annurev.publhealth.23.112001.112349

5 Finney LJ, Feary JR, Leonardi-Bee J, Gordon SB, Mortimer K. Chronic obstructive pulmonary disease in sub-Saharan Africa: a systematic review. Int J Tuberc Lung Dis. 2013;17:583-9. Medline:23394105 doi:10.5588/ijtld.12.0619

6 van Gemert F, Kirenga B, Chavannes N, Kamya M, Luzige S, Musinguzi P, et al. Prevalence of chronic obstructive pulmonary disease and associated risk factors in Uganda (FRESH AIR Uganda): a prospective cross-sectional observational study. Lancet Glob Health. 2015;3:e44-51. Medline:25539969 doi:10.1016/S2214-109X(14)70337-7

7 Siddharthan T, Grigsby MR, Goodman D, Chowdhury M, Rubinstein A, Irazola V, et al. Association between household air pollution exposure and chronic obstructive pulmonary disease outcomes in 13 low- and middle-income country settings. Am J Respir Crit Care Med. 2018;197:611-20. Medline:29323928 doi:10.1164/rccm.201709-18610C

8 Boudewijns EA, Babu GR, Salvi S, Sheikh A, van Schayck OC. Chronic obstructive pulmonary disease: a disease of old age? J Glob Health. 2018;8:020306. Medline:30333921 doi:10.7189/jogh.08.020306

9 Uganda Bureau of Statistics. National Population and Housing Census 2014. Available: http://www.ubos.org/2014-census/census-2014-final-results/. Accessed: 3 January 2019.

10 Tsai AC, Kakuhikire B, Mushavi R, Vorechovska D, Perkins JM, McDonough AQ, et al. Population-based study of intra-household gender differences in water insecurity: reliability and validity of a survey instrument for use in rural Uganda. J Water Health. 2016;14:280-92. Medline:27105413 doi:10.2166/wh.2015.165

11 Tsai AC, Bangsberg DR, Frongillo EA, Hunt PW, Muzoora C, Martin JN, et al. Food insecurity, depression and the modifying role of social support among people living with HIV/AIDS in rural Uganda. Soc Sci Med. 2012;74:2012-9. Medline:22513248 doi:10.1016/j.socscimed.2012.02.033

12 World Health Organization. The STEPS Instrument and Support Materials. 2017. Available: http://www.who.int/chp/ steps/riskfactor/en/. Accessed: 3 January 2019

13 Uganda Ministry of Health. Uganda National Policy Guidelines for HIV Counseling and Testing. 2005. Available: http:// library.health.go.ug/publications/leadership-and-governance-governance/policy-documents/uganda-national-policy-guidelin-0. Accessed: 3 January 2019

14 Miller MR, Hankinson J, Brusasco V, Burgos F, Casaburi R, Coates A, et al. Standardisation of spirometry. Eur Respir J. 2005;26:319-38. Medline:16055882 doi:10.1183/09031936.05.00034805

15 Hankinson JL, Odencrantz JR, Fedan KB. Spirometric reference values from a sample of the general U.S. population. Am J Respir Crit Care Med. 1999;159:179-87. Medline:9872837 doi:10.1164/ajrccm.159.1.9712108

16 Pellegrino R, Viegi G, Brusasco V, Crapo RO, Burgos F, Casaburi R, et al. Interpretative strategies for lung function tests. Eur Respir J. 2005;26:948-68. Medline:16264058 doi:10.1183/09031936.05.00035205

17 Musafiri S, van Meerbeeck JP, Musango L, Derom E, Brusselle G, Joos G, et al. Spirometric reference values for an East-African population. Respiration. 2013;85:297-304. Medline:22584423 doi:10.1159/000337256

18 Filmer D, Pritchett LH. Estimating wealth effects without expenditure data—or tears: an application to educational enrollments in states of India. Demography. 2001;38:115-32. Medline:11227840

19 Burt RS. Network items and the general social survey. Soc Networks. 1984;6:293-339. doi:10.1016/03788733(84)90007-8

20 Myroniuk TW, Anglewicz P. Does social participation predict better health? A Longitudinal study in rural Malawi. J Health Soc Behav. 2015;56:552-73. Medline:26646745 doi:10.1177/0022146515613416

21 Ballard T, Coates J, Swindale A, Deitchler M. Household hunger scale: indicator definition and measurement guide. Food and Nutrition Technical Assistance (FANTA). 2011;2.

22 Cole SR, Hernan MA. Constructing inverse probability weights for marginal structural models. Am J Epidemiol. 2008;168:656-64. Medline:18682488 doi:10.1093/aje/kwn164

23 UNAIDS. UNAIDS Country Factsheets: Uganda, 2016. Available: http://www.unaids.org/en/regionscountries/countries/ uganda. Accessed: 3 January 2019

24 Magitta NF, Walker RW, Apte KK, Shimwela MD, Mwaiselage JD, Sanga AA, et al. Prevalence, risk factors and clinical correlates of COPD in a rural setting in Tanzania. Eur Respir J. 2018;51: 1700182. Medline:29386343 doi:10.1183/13993003.00182-2017

25 Pefura-Yone EW, Kengne AP, Balkissou AD, Magne-Fotso CG, Ngo-Yonga M, Boulleys-Nana JR, et al. Prevalence of obstructive lung disease in an African country using definitions from different international guidelines: a community based cross-sectional survey. BMC Res Notes. 2016;9:124. Medline:26917543 doi:10.1186/s13104-015-1731-6

26 Meghji J, Nadeau G, Davis KJ, Wang D, Nyirenda MJ, Gordon SB, et al. Noncommunicable lung disease in sub-saharan africa. a community-based cross-sectional study of adults in urban Malawi. Am J Respir Crit Care Med. 2016;194:6776. Medline:26788760 doi:10.1164/rccm.201509-1807OC 
27 Obaseki DO, Erhabor GE, Gnatiuc L, Adewole OO, Buist SA, Burney PG. Chronic airflow obstruction in a Black African population: results of BOLD study, Ile-Ife, Nigeria. COPD. 2016;13:42-9. Medline:26451840 doi:10.3109/15412 555.2015 .1041102

28 Musafiri S, van Meerbeeck J, Musango L, Brusselle G, Joos G, Seminega B, et al. Prevalence of atopy, asthma and COPD in an urban and a rural area of an African country. Respir Med. 2011;105:1596-605. Medline:21783353 doi:10.1016/j. rmed.2011.06.013

29 Fullerton DG, Suseno A, Semple S, Kalambo F, Malamba R, White S, et al. Wood smoke exposure, poverty and impaired lung function in Malawian adults. Int J Tuberc Lung Dis. 2011;15:391-8. Medline:21333109

30 Khelafi R, Aissanou A, Tarsift S, Skander F. Epidemiology of chronic obstructive pulmonary disease in Algiers. Rev Mal Respir. 2011;28:32-40. Medline:21277472 doi:10.1016/j.rmr.2010.06.026

31 Martins P, Rosado-Pinto J, do Ceu Teixeira M, Neuparth N, Silva O, Tavares H, et al. Under-report and underdiagnosis of chronic respiratory diseases in an African country. Allergy. 2009;64:1061-7. Medline:19210360 doi:10.1111/j.13989995.2009.01956.x

32 Girdler-Brown BV, White NW, Ehrlich RI, Churchyard GJ. The burden of silicosis, pulmonary tuberculosis and COPD among former Basotho goldminers. Am J Ind Med. 2008;51:640-7. Medline:18566985 doi:10.1002/ajim.20602

33 Buist AS, McBurnie MA, Vollmer WM, Gillespie S, Burney P, Mannino DM, et al. International variation in the prevalence of COPD (the BOLD Study): a population-based prevalence study. Lancet. 2007;370:741-50. Medline:17765523 doi:10.1016/S0140-6736(07)61377-4

34 Gathuru IM, Bunker CH, Ukoli FA, Egbagbe EE. Differences in rates of obstructive lung disease between Africans and African Americans. Ethn Dis. 2002;12:S3-107-13. Medline:12477165

35 Oleru UG, Onyekwere C. Exposures to polyvinyl chloride, methyl ketone and other chemicals. The pulmonary and non-pulmonary effect. Int Arch Occup Environ Health. 1992;63:503-7. Medline:1577530 doi:10.1007/BF00572117

36 Myers JE, Cornell JE. Respiratory health of brickworkers in Cape Town, South Africa. Symptoms, signs and pulmonary function abnormalities. Scand J Work Environ Health. 1989;15:188-94. Medline:2781248 doi:10.5271/sjweh.1863

37 Wicht CL, de Kock MA, van Wyk Kotze TJ. An epidemiological study of the diffuse obstructive pulmonary syndrome. S Afr Med J. 1977;52 suppl:1-15. Medline:609980

38 Salvi S, Barnes PJ. Is exposure to biomass smoke the biggest risk factor for COPD globally? Chest. 2010;138:3-6. Medline:20605806 doi:10.1378/chest.10-0645

39 Amaral AFS, Patel J, Kato BS, Obaseki DO, Lawin H, Tan WC, et al. Airflow obstruction and use of solid fuels for cooking or heating: BOLD results. Am J Respir Crit Care Med. 2018;197:595-610. Medline:28895752 doi:10.1164/rccm.201701-02050C

40 Zhao D, Zhou Y, Jiang C, Zhao Z, He F, Ran P. Small airway disease: A different phenotype of early stage COPD associated with biomass smoke exposure. Respirology. 2018,23:198-205. Medline:28906034 doi:10.1111/resp.13176

41 Ramirez-Venegas A, Sansores RH, Quintana-Carrillo RH, Velazquez-Uncal M, Hernandez-Zenteno RJ, Sanchez-Romero C, et al. FEV1 decline in patients with chronic obstructive pulmonary disease associated with biomass exposure. Am J Respir Crit Care Med. 2014;190:996-1002. Medline:25172140 doi:10.1164/rccm.201404-07200C

42 Menezes AM, Perez-Padilla R, Wehrmeister FC, Lopez-Varela MV, Muino A, Valdivia G, et al. FEV1 is a better predictor of mortality than FVC: the PLATINO cohort study. PLoS One. 2014;9:e109732. Medline:25285441 doi:10.1371/journal.pone.0109732

43 Pampel F. Tobacco use in sub-Sahara Africa: estimates from the demographic health surveys. Soc Sci Med. 2008;66:177283. Medline:18249479 doi:10.1016/j.socscimed.2007.12.003

44 North CM, Allen JG, Okello S, Sentongo R, Kakuhikire B, Ryan ET, et al. HIV infection, pulmonary tuberculosis, and COPD in rural Uganda: A Cross-Sectional Study. Lung. 2018;196:49-57. Medline:29260309 doi:10.1007/s00408-0170080-8

45 North CM, Valeri L, Hunt PW, Mocello AR, Martin JN, Boum Y II, et al. Cooking fuel and respiratory symptoms among people living with HIV in rural Uganda. ERJ Open Res. 2017;3.

46 van Gemert F, Chavannes N, Nabadda N, Luzige S, Kirenga B, Eggermont C, et al. Impact of chronic respiratory symptoms in a rural area of sub-Saharan Africa: an in-depth qualitative study in the Masindi district of Uganda. Prim Care Respir J. 2013;22:300-5. Medline:23817677 doi:10.4104/pcrj.2013.00064

47 Mannino DM, Buist AS. Global burden of COPD: risk factors, prevalence, and future trends. Lancet. 2007;370:765-73. Medline:17765526 doi:10.1016/S0140-6736(07)61380-4

48 National Household Survey 2016/2017. Uganda Bureau of Statistics. Available: www.ubos.org. Accessed: 3 January 2019.

49 Kumar R, Seibold MA, Aldrich MC, Williams LK, Reiner AP, Colangelo L, et al. Genetic ancestry in lung-function predictions. N Engl J Med. 2010;363:321-30. Medline:20647190 doi:10.1056/NEJMoa0907897

50 Amaral AF, Coton S, Kato B, Tan WC, Studnicka M, Janson C, et al. Tuberculosis associates with both airflow obstruction and low lung function: BOLD results. Eur Respir J. 2015;46:1104-12. Medline:26113680 doi:10.1183/13993003.023252014

51 Adeloye D, Chua S, Lee C, Basquill C, Papana A, Theodoratou E, et al. Global and regional estimates of COPD prevalence: Systematic review and meta-analysis. J Glob Health. 2015;5:020415. Medline:26755942 doi:10.7189/jogh.05.020415

52 de Marco R, Accordini S, Cerveri I, Corsico A, Sunyer J, Neukirch F, et al. An international survey of chronic obstructive pulmonary disease in young adults according to GOLD stages. Thorax. 2004;59:120-5. Medline:14760151 doi:10.1136/ thorax.2003.011163

53 Amaral AFS, Strachan DP, Burney PGJ, Jarvis DL. Female smokers are at greater risk of airflow obstruction than male smokers. UK Biobank. Am J Respir Crit Care Med. 2017;195:1226-35. Medline:28075609 doi:10.1164/rccm.201608-15450C 
54 Hardin M, Cho MH, Sharma S, Glass K, Castaldi PJ, McDonald ML, et al. Sex-based genetic association study identifies celsrl as a possible chronic obstructive pulmonary disease risk locus among women. Am J Respir Cell Mol Biol. 2017;56:332-41. Medline:27854507 doi:10.1165/rcmb.2016-01720C

55 Gordon SB, Bruce NG, Grigg J, Hibberd PL, Kurmi OP, Lam KB, et al. Respiratory risks from household air pollution in low and middle income countries. Lancet Respir Med. 2014;2:823-60. Medline:25193349 doi:10.1016/S22132600(14)70168-7

56 Akanbi MO, Taiwo BO, Achenbach CJ, Ozoh OB, Obaseki DO, Sule H, et al. HIV associated chronic obstructive pulmonary disease in Nigeria. J AIDS Clin Res. 2015;6:453. Medline:26236557 doi:10.4172/2155-6113.1000453

57 Fitzpatrick ME, Nouraie M, Gingo MR, Camp D, Kessinger CJ, Sincebaugh JB, et al. Novel relationships of markers of monocyte activation and endothelial dysfunction with pulmonary dysfunction in HIV-infected persons. AIDS. 2016;30:1327-39. Medline:26990629 doi:10.1097/QAD.0000000000001092

58 Smith JA, Woodcock A. Chronic Cough. N Engl J Med. 2016;375:1544-51. Medline:27797316 doi:10.1056/NEJMcp 1414215

59 Sani MU, Cotter G, Davison BA, Mayosi BM, Damasceno A, Edwards C, et al. Symptoms and signs of heart failure at admission and discharge and outcomes in the Sub-Saharan Acute Heart Failure (THESUS-HF) Registry. J Card Fail. 2017;23:739-42. Medline:27664511 doi:10.1016/j.cardfail.2016.09.016

60 van Riet EE, Hoes AW, Limburg A, Landman MA, van der Hoeven H, Rutten FH. Prevalence of unrecognized heart failure in older persons with shortness of breath on exertion. Eur J Heart Fail. 2014;16:772-7. Medline:24863953 doi:10.1002/ ejhf. 110

61 Muthalaly RG, Koplan BA, Albano A, North C, Campbell JI, Kakuhikire B, et al. Low population prevalence of atrial fibrillation in rural Uganda: A community-based cross-sectional study. Int J Cardiol. 2018;271:87-91. Medline:29859712 doi:10.1016/j.ijcard.2018.05.074

62 Murray CJ, Ortblad KF, Guinovart C, Lim SS, Wolock TM, Roberts DA, et al. Global, regional, and national incidence and mortality for HIV, tuberculosis, and malaria during 1990-2013: a systematic analysis for the Global Burden of Disease Study 2013. Lancet. 2014;384:1005-70. Medline:25059949 doi:10.1016/S0140-6736(14)60844-8

63 Wiemken TL, Peyrani P, Ramirez JA. Global changes in the epidemiology of community-acquired pneumonia. Semin Respir Crit Care Med. 2012;33:213-9. Medline:22718207 doi:10.1055/s-0032-1315633

64 Amaral AF, Coton S, Kato B, Tan WC, Studnicka M, Janson C, et al. Tuberculosis associates with both airflow obstruction and low lung function: BOLD results. Eur Respir J. 2015;46:1104-12. Medline:26113680 doi:10.1183/13993003.023252014

65 Hayden LP, Hobbs BD, Cohen RT, Wise RA, Checkley W, Crapo JD, et al. Childhood pneumonia increases risk for chronic obstructive pulmonary disease: the COPDGene study. Respir Res. 2015;16:115. Medline:26392057 doi:10.1186/ s12931-015-0273-8

66 Sack C, Vedal S, Sheppard L, Raghu G, Barr RG, Podolanczuk A, et al. Air pollution and subclinical interstitial lung disease: the Multi-Ethnic Study of Atherosclerosis (MESA) air-lung study. Eur Respir J. 2017;50: 1700559. Medline:29217611 doi:10.1183/13993003.00559-2017

67 Calderon-Garciduenas L, Mora-Tiscareno A, Fordham LA, Chung CJ, Valencia-Salazar G, Flores-Gomez S, et al. Lung radiology and pulmonary function of children chronically exposed to air pollution. Environ Health Perspect. 2006;114:1432-7. Medline:16966101 doi:10.1289/ehp.8377

68 Song W-J, Chang Y-S, Faruqi S, Kim J-Y, Kang M-G, Kim S, et al. The global epidemiology of chroinc cough in adults: a systematic review and meta-analysis. Eur Respir J. 2015;45:1479-81. Medline:25657027 doi:10.1183/09031936.00218714

69 Sekandi JN, Neuhauser D, Smyth K, Whalen CC. Active case finding of undetected tuberculosis among chronic coughers in a slum setting in Kampala, Uganda. Int J Tuberc Lung Dis. 2009;13:508-13. Medline:19335958

70 Desalu OO, Salami AK, Fawibe AE. Prevalence of cough among adults in an urban community in Nigeria. West Afr J Med. 2011;30:337-41. Medline:22752821

71 Nriagu J, Robins T, Gary L, Liggans G, Davila R, Supuwood K, et al. Prevalence of asthma and respiratory symptoms in south-central Durban, South Africa. Eur J Epidemiol. 1999;15:747-55. Medline:10555619 doi:10.1023/A:1007653709188

72 Banda HT, Thomson R, Mortimer K, Bello GAF, Mbera GB, Malmborg R, et al. Community prevalence of chronic respiratory symptoms in rural Malawi: Implications for policy. PLoS One. 2017;12:e0188437. Medline:29216193 doi:10.1371/ journal.pone.0188437

73 Walraven GE, Nyan OA, Van Der Sande MA, Banya WA, Ceesay SM, Milligan PJ, et al. Asthma, smoking and chronic cough in rural and urban adult communities in The Gambia. Clin Exp Allergy. 2001;31:1679-85. Medline:11696043 doi:10.1046/j.1365-2222.2001.01094.x

74 Kelsall A, Decalmer S, McGuinness K, Woodcock A, Smith JA. Sex differences and predictors of objective cough frequency in chronic cough. Thorax. 2009;64:393-8. Medline:19131447 doi:10.1136/thx.2008.106237 